\title{
Pengaruh Variasi Waktu Perendaman dalam Ekstrak Daun Teh Hijau (Camellia sinensis) terhadap Stabilitas Dimensi Alginat
}

\author{
Yoghi B. Prabowo, ${ }^{1 *}$ Natalia P. Ibrahim,,${ }^{1 *}$ Indah Saraswati ${ }^{2}$
}

\author{
${ }^{1}$ Departemen Kedokteran Gigi Fakultas Kedokteran Universitas Diponegoro, Semarang, \\ Jawa Tengah, Indonesia \\ ${ }^{2}$ Departemen Kedokteran Universitas Diponegoro Semarang, Jawa Tengah, Indonesia \\ *Kedua Penulis memiliki kontribusi yang sama dalam penulisan naskah. \\ Email: is.sjafari@gmail.com
}

\begin{abstract}
Alginate has an imbibition property if it comes in contact with water that will affect the dimensional stability. Green tea (Camellia sinensis) contains phenolic compounds which can minimize the imbibition process while it is used in disinfection of alginate impression. This study was aimed to analyze the differences in the dimensional stability of alginate impressions after immersion in green tea leaf extract based on time variation. This was an experimental post-test laboratory study only. The one way Anova test on the anteroposterior and mediolateral dimensions showed that variation of immersion time in 50\% green tea leaf extract could affect the dimensional stability. Moreover, the post hoc Games Howell test on the anteroposterior dimension and the post hoc LSD test on the mediolateral dimension resulted that there were significant differences between the control group and the groups of 5 minutes, 15 minutes, 30 minutes, and 50 minutes of immersion. Among all alginate impressions, the one immersed for 15 minutes was still in accordance with the standard of the American Dental Association. In conclusion, 15-minute immersion of alginate impression in 50\% green tea leaf extract was the best time variation.
\end{abstract}

Keywords: alginate, dimensional stability, green tea leaf extract $50 \%$

\begin{abstract}
Abstrak: Alginat memiliki sifat imbibisi bila berkontak dengan air yang akan memengaruhi stabilitas dimensi alginat. Teh hijau (Camellia sinensis) mengandung senyawa fenol yang mampu meminimalkan terjadinya proses imbibisi. Penelitian ini bertujuan untuk menganalisis perbedaan stabilitas dimensi alginat setelah direndam berdasarkan variasi waktu dalam ekstrak daun teh hijau. Jenis penelitian ialah eksperimental laboratorik post-test only. Stabilitas dimensi diketahui melalui selisih jarak anteroposterior (A'-B') dan mediolateral (B'-C') master die dengan die stone. Hasil uji one way Anova terhadap dimensi anteroposterior dan mediolateral mendapatkan adanya pengaruh variasi waktu perendaman dalam ekstrak daun teh hijau 50\% terhadap stabilitas dimensi. Selanjutnya hasil uji post hoc Games Howell terhadap dimensi anteroposterior dan uji post hoc $L S D$ terhadap dimensi mediolateral mendapatkan perbedaan bermakna antara kelompok kontrol dengan kelompok perendaman 5 menit, 15 menit, 30 menit, dan 50 menit. Hasil perendaman cetakan alginat yang masih sesuai dengan standar American Dental Association ialah perendaman selama 15 menit. Simpulan penelitian ini ialah perendaman cetakan alginat dalam ekstrak daun teh hijau 50\% yang terbaik ialah selama 15 menit.
\end{abstract}

Kata kunci: alginat, stabilitas dimensi, ekstrak daun teh hijau 50\%

\section{PENDAHULUAN}

Menurut RISKESDAS tahun 2018, Indonesia memiliki prevalensi kehilangan gigi sebesar 9\% dan terjadi pada usia 65 tahun ke atas. Hal tersebut dapat diatasi dengan pembuatan gigi tiruan. Pada pembuatan gigi tiruan dalam bidang prostodonsia dibutuhkan tahap pencetakan rahang terlebih dahulu dengan menggunakan bahan cetak. Bahan cetak merupakan bahan yang 
digunakan untuk mendapatkan cetakan negatif dari gigi dan jaringan sekitar gigi. ${ }^{1}$ Secara umum bahan cetak diklasifikasikan dalam dua kelompok yaitu bahan cetak elastis dan non elastis. ${ }^{2}$

Bahan cetak elastis dapat mencetak struktur keras maupun lunak dari rongga mulut secara akurat termasuk undercut dan celah interproksimal. Bahan cetak nonelastis tidak dapat melalui undercut sehingga penggunaannya terbatas pada pasien edentulus. Salah satu bahan cetak elastis yang paling banyak digunakan ialah hidrokoloid ireversibel atau alginat. ${ }^{2}$

Alginat merupakan bahan yang paling banyak digunakan karena memiliki kelebihan yaitu mudah dimanipulasi, tidak memerlukan banyak peralatan, harga relatif murah, dan memiliki aroma yang menyegarkan seperti permen karet sehingga nyaman untuk pasien dan mengurangi refleks muntah. Kekurangan alginat yaitu masalah yang berhubungan dengan stabilitas dimensi dan hasil cetakan yang kurang detil. ${ }^{3}$ Alginat membutuhkan desinfektan yang mampu meminimalkan terjadinya imbibisi saat dilakukannya desinfeksi. Pusat Pengendalian Penyakit dan American Dental Association (ADA) merekomendasikan desinfeksi hasil cetakan alginat dilakukan segera setelah dikeluarkan dari mulut. Namun, hal penting yang perlu diperhatikan juga ialah larutan desinfektan tidak hanya efektif sebagai agen antimikroba tetapi juga tidak boleh menurunkan keakuratan bahan cetak. ${ }^{4}$

Larutan desinfektan seperti deconex dan glutaraldehyde $2 \%$ pada penelitian sebelumnya tidak disarankan karena menyebabkan perubahan dimensi. ${ }^{5}$ Bahan desinfektan lainnya seperti sodium hipoklorit juga tidak disarankan karena menyebabkan korosi pada sendok cetak logam dan menyebabkan iritasi kulit. ${ }^{6}$ Untuk menghindari hal tersebut, dapat digantikan dengan desinfektan alami yang berfungsi sebagai antimikroba. Katekin dan flavanol merupakan senyawa yang bersifat antimikroba dan keduanya terkandung dalam teh hijau (Camellia sinensis). ${ }^{7}$

Teh hijau (Camellia sinensis) mengan- dung substansi fenol dan bukan fenol. Fenol dalam daun teh hijau tidak mudah untuk berikatan dengan larutan zat lain sehingga tidak mudah terjadi proses imbibisi jika digunakan dalam desinfeksi cetakan alginat. ${ }^{6}$ Oleh karena itu, teh hijau dapat dijadikan sebagai alternatif bahan desinfektan alami.

Terdapat dua metode dalam teknik aplikasi desinfektan pada alginat yaitu perendaman dan penyemprotan. Teknik perendaman dapat menjangkau seluruh permukaan bahan cetak dan dapat terhindar dari kontaminasi bakteri, sedangkan teknik penyemprotan tidak dapat menjamin meratanya desinfektan pada permukaan bahan cetak. ${ }^{8}$

Dengan melihat adanya keterbatasan penggunaan desinfektan maka penulis tertarik untuk menganalisis perbedaan stabilitas dimensi alginat setelah direndam berdasarkan variasi waktu dalam ekstrak daun teh hijau yang telah diketahui mengandung bahan alami fenol.

\section{METODE PENELITIAN}

Penelitian ini dilakukan di Laboratorium PreKlinik Kedokteran Gigi, Universitas Diponegoro, Semarang. Jenis penelitian ialah eksperimental laboratorik dengan post-test only control group design. Terdapat 25 sampel penelitian terdiri dari 1 kelom-pok kontrol tanpa direndam dan 4 kelompok perlakuan yang direndam dalam ekstrak daun teh hijau 50\% selama 5 menit, 15 menit, 30 menit, dan 50 menit. Larutan ekstrak daun teh hijau 50\% diperoleh dari proses perebusan daun teh hijau segar 300 gr dengan akuades steril $1000 \mathrm{ml}$, kemudian disaring dan menghasilkan ekstrak $500 \mathrm{ml}$. Selanjutnya ekstrak tersebut ditambahkan lagi $500 \mathrm{ml}$ akuades steril sehingga menghasilkan larutan ekstrak daun teh hijau 50\%. Pembuatan cetakan alginat dilakukan dengan cara bahan cetak alginat dan air diaduk dengan teknik pengadukan angka delapan menggunakan spatula pada rubber bowl hingga homogen, kemudian bahan cetak dimasukkan ke dalam sendok cetak no 2. Pencetakan dilakukan pada master die (Gambar 1) selama 1-2 menit. Setelah bahan cetak mengeras, cetakan dilepas. 


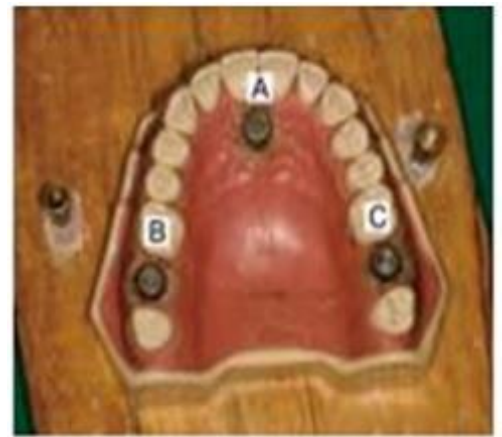

Master die

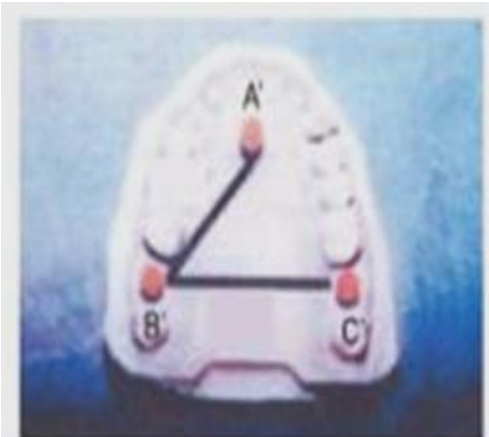

Die stone

Gambar 1. Master Die dan Die Stone. Sumber: Farzin M, Panahandeh H, $2010 .^{9}$

Pengukuran stabilitas dimensi diketahui dari selisih jarak dimensi anteroposterior pada die stone (A'B') dan master die (AB) serta selisih jarak dimensi mediolateral die stone (B'C') dan master die (BC) dengan menggunakan sliding kaliper digital. Pengukuran die stone maupun master die dilakukan sebanyak tiga kali dan diambil reratanya.

Data yang diperoleh dianalisis dengan uji Sapphiro-Wilk untuk melihat sebaran data, kemudian uji Lavene, dilanjutkan dengan uji one way Annova, uji post hoc Games-Howell untuk dimensi anteroposte- rior dan post hoc $L S D$ untuk dimensi mediolateral.

\section{HASIL PENELITIAN}

Perhitungan stabilitas dimensi diawali dengan pengukuran pada master die dan diperoleh jarak dimensi anteroposterior sebesar 22,17 mm dan jarak dimensi mediolateral sebesar $33 \mathrm{~mm}$. Gambar 1 dan 2 memperlihatkan pengukuran dimensi cetakan alginat pada dimensi anteroposterior dan mediolateral.

\section{Die Stone dimensi anteroposterior}

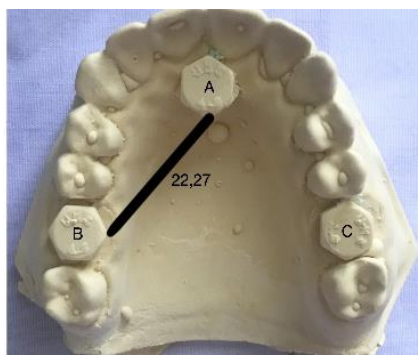

Kontrol

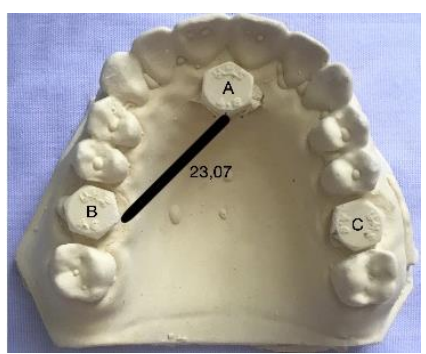

Perendaman selama 5 menit

\section{Die Stone dimensi mediolateral}

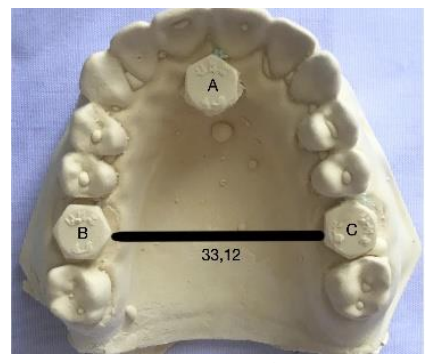

Kontrol

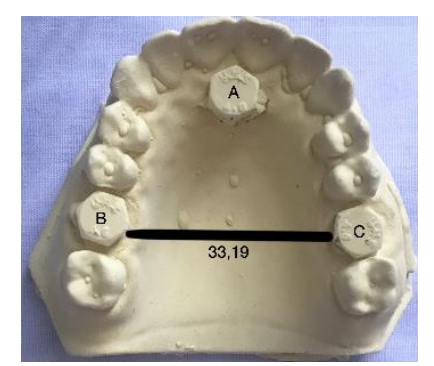

Perendaman selama 5 menit 


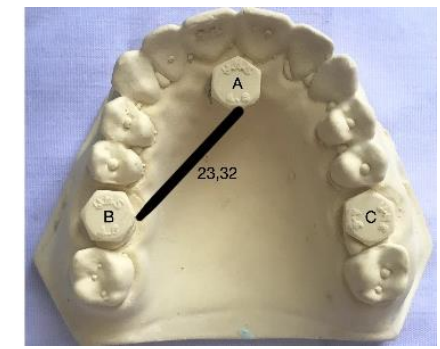

Perendaman selama 15 menit

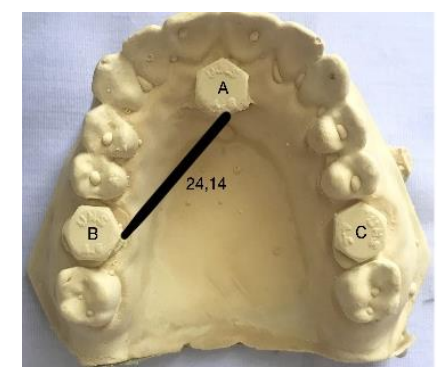

Perendaman selama 30 menit

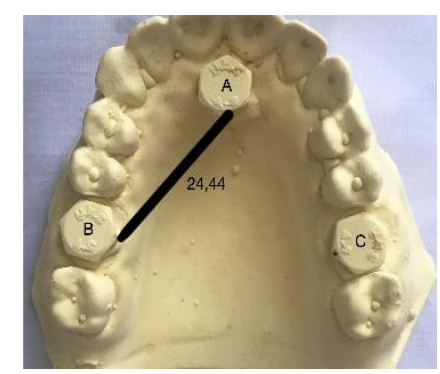

Perendaman selama 50 menit

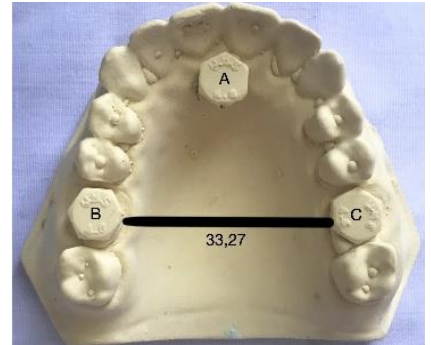

Perendaman selama 15 menit

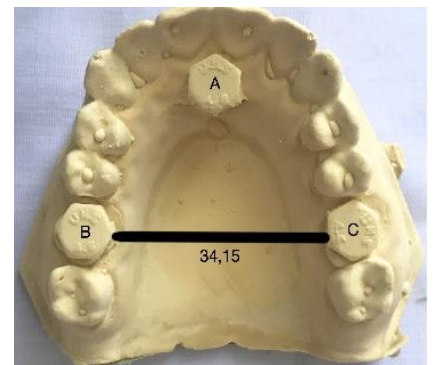

Perendaman selama 30 menit

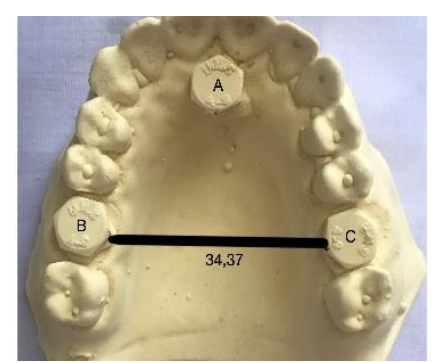

Perendaman selama 50 menit

Gambar 2. Die stone dimensi anteroposterior dan mediolateral dengan perendaman dalam ekstrak daun teh hijau 50\% selama 5, 15, 30, dan 50 menit

Tabel 1 dan 2 menunjukkan bahwa perbedaan stabilitas dimensi cetakan alginat pada kelompok kontrol memiliki selisih paling kecil daripada kelompok perlakuan yang lain, sedangkan selisih jarak terbesar terdapat pada hasil cetakan alginat yang direndam selama 50 menit.

Hasil uji normalitas dengan SaphiroWilk menunjukkan data jarak anteroposterior dan jarak mediolateral pada seluruh kelompok perlakuan memiliki nilai p>0,05 yang berarti sebaran data yang normal. Hasil Uji one way Anova untuk dimensi anteroposterior dan mediolateral ialah $\mathrm{p}=0,00(\mathrm{p}<0,05)$ yang berarti terdapat pengaruh variasi waktu perendaman ekstrak daun teh hijau 50\% terhadap stabilitas dimensi.

Tabel 3 dan 4 menunjukkan perbedaan stabilitas dimensi yang direndam berdasarkan variasi waktu dalam ekstrak daun teh hijau dan tanpa direndam. Perbedaan stabilitas dimensi ini dapat terlihat dari bertambahnya ukuran dimensi anteroposterior dan mediolateral yang diukur pada die stone.

Uji statistika dilanjutkan dengan menggunakan uji post hoc Games-Howell karena data tidak homogen. Hasil uji ini mendapatkan perbedaan bermakna dari jarak dimensi anteroposterior antar kelompok kontrol dengan perendaman 5 menit, 15 menit, 30 menit, dan 50 menit.

Uji statistika dilanjutkan dengan menggunakan uji post hoc LSD karena data homogen. Hasil uji mendapatkan perbedaan bermakna dimensi mediolateral antar kelompok kontrol dengan perendaman selama 
15 menit, 30 menit, dan 50 menit, namun, kelompok kontrol dengan perendaman terdapat perbedaan tidak bermakna pada selama 5 menit.

Tabel 1. Pengukuran stabilitas dimensi anteroposterior

\begin{tabular}{ccccc}
\hline Perlakuan & $\begin{array}{c}\text { Rerata Jarak } \\
\text { Dimensi } \\
\text { Anteroposterior }\end{array}$ & $\begin{array}{c}\text { Selisih dengan Master } \\
\text { Die } \text { (Stabilitas } \\
\text { Dimensi) }\end{array}$ & $\begin{array}{c}\text { Std. } \\
\text { Deviasi }\end{array}$ & $\begin{array}{c}\text { Batas Toleransi } \\
\mathbf{( 0 , 5 \% )}\end{array}$ \\
\hline Kontrol & $22,27 \mathrm{~mm}$ & $0,10 \mathrm{~mm}$ & 0,06 & \\
5 Menit & $23,07 \mathrm{~mm}$ & $0,90 \mathrm{~mm}$ & 0,17 & \\
15 Menit & $23,32 \mathrm{~mm}$ & $1,15 \mathrm{~mm}$ & 0,22 & $0,11 \%$ \\
30 Menit & $24,14 \mathrm{~mm}$ & $1,97 \mathrm{~mm}$ & 0,18 & \\
50 Menit & $24,44 \mathrm{~mm}$ & $2,27 \mathrm{~mm}$ & 0,04 & \\
\hline
\end{tabular}

Tabel 2. Pengukuran stabilitas dimensi mediolateral

\begin{tabular}{ccccc}
\hline Perlakuan & $\begin{array}{c}\text { Rerata Jarak } \\
\text { Dimensi } \\
\text { Mediolateral }\end{array}$ & $\begin{array}{c}\text { Selisih dengan Master } \\
\text { Die } \text { (Stabilitas } \\
\text { Dimensi) }\end{array}$ & $\begin{array}{c}\text { Std. } \\
\text { Deviasi }\end{array}$ & $\begin{array}{c}\text { Batas Toleransi } \\
\mathbf{( 0 , 5 \% )}\end{array}$ \\
\hline Kontrol & $33,12 \mathrm{~mm}$ & $0,12 \mathrm{~mm}$ & 0,09 & \\
5 Menit & $33,19 \mathrm{~mm}$ & $0,19 \mathrm{~mm}$ & 0,08 & \\
15 Menit & $33,27 \mathrm{~mm}$ & $0,27 \mathrm{~mm}$ & 0,04 & $0,17 \%$ \\
30 Menit & $34,15 \mathrm{~mm}$ & $1,15 \mathrm{~mm}$ & 0,08 & \\
50 Menit & $34,37 \mathrm{~mm}$ & $1,37 \mathrm{~mm}$ & 0,10 & \\
\hline
\end{tabular}

Tabel 3. Hasil uji post hoc Games-Howell pada jarak anteroposterior

\begin{tabular}{|c|c|c|c|c|c|}
\hline \multirow{2}{*}{ Perlakuan } & \multicolumn{5}{|c|}{ Perlakuan } \\
\hline & Kontrol & 5 Menit & 15 Menit & 30 Menit & 50 Menit \\
\hline Kontrol & - & $0,001 *$ & $0,001 *$ & $0,000 *$ & $0,000^{*}$ \\
\hline 5 Menit & $0,001 *$ & - & 0,400 & $0,000^{*}$ & $0,000^{*}$ \\
\hline 15 Menit & $0,001 *$ & 0,400 & - & $0,002^{*}$ & $0,001 *$ \\
\hline 30 Menit & $0,000^{*}$ & $0,000^{*}$ & $0,002 *$ & - & 0,084 \\
\hline 50 Menit & $0,000^{*}$ & $0,000^{*}$ & $0,001 *$ & 0,084 & - \\
\hline
\end{tabular}

Keterangan :*Bermakna $p<0,05$

Tabel 4. Hasil uji post Hoc LSD pada jarak mediolateral

\begin{tabular}{cccccc}
\hline Perlakuan & Kontrol & 5 Menit & $\begin{array}{c}\text { Perlakuan } \\
15 \text { Menit }\end{array}$ & 30 Menit & 50 Menit \\
\hline Kontrol & - & 0,186 & $0,011^{*}$ & $0,000^{*}$ & $0,000^{*}$ \\
5 Menit & 0,186 & - & 0,163 & $0,000^{*}$ & $0,000^{*}$ \\
15 Menit & $0,011^{*}$ & 0,163 & - & $0,000^{*}$ & $0,000^{*}$ \\
30 Menit & $0,000^{*}$ & $0,000^{*}$ & $0,000^{*}$ & - & $0,032^{*}$ \\
50 Menit & $0,000^{*}$ & $0,000^{*}$ & $0,000^{*}$ & $0,032^{*}$ & - \\
\hline
\end{tabular}

Keterangan :*Bermakna $p<0,05$ 


\section{BAHASAN}

Hasil penelitian sebelumnya oleh Wirayuni et al. ${ }^{10}$ untuk mendesinfeksi alginat dengan cara perendaman pada ekstrak mengkudu (Morinda citrifolia Linn) 12\%, $25 \%$, dan $50 \%$ menunjukkan perubahan stabilitas dimensi yang besar pada konsentrasi $12 \%$ dan $25 \%$ dibanding perubahan stabilitas dimensi pada konsentrasi $50 \%$. Hal ini terjadi karena semakin rendah konsentrasi larutan, maka larutan akan semakin encer yang menyebabkan penyerapan lebih banyak pada cetakan alginat. ${ }^{10}$

Proses pembuatan ekstrak daun teh hijau 50\% dilakukan dengan merebus daun teh hijau segar menggunakan pelarut air karena pelarut polar memudahkan senyawa fenol larut dalam air. ${ }^{11}$ Metode ekstraksi dilakukan dengan perebusan karena ekstraksi dapat berlangsung dengan efisien dan senyawa dalam sampel secara lebih efektif dapat ditarik oleh pelarut. ${ }^{12}$

Hasil cetakan alginat mengandung $85 \%$ air sehingga memungkinkan untuk mengalami imbibisi maupun sineresis. Hasil cetakan dapat dikatakan baik apabila akurasinya terjamin dan memiliki stabilitas dimensi sampai nanti akan dituangkan gipsum untuk dijadikan model kerja. ${ }^{3}$ Akurasi dan stabilitas dimensi alginat merupakan hal penting untuk keberhasilan hasil cetakan secara menyeluruh. ${ }^{13}$

Hasil uji one way Anova mendapatkan nilai $\mathrm{p}=0,00(\mathrm{p}<0,05)$ yang berarti terdapat pengaruh variasi waktu perendaman dalam ekstrak daun teh hijau 50\% terhadap stabilitas dimensi jarak anteroposterior dan jarak mediolateral. Hal ini sejalan dengan penelitian Santoso et $\mathrm{al}^{13}$ yang menyatakan terdapat pengaruh lama perendaman cetakan alginat terhadap stabilitas dimensi, yaitu semakin lama perendaman maka perubahan stabilitas dimensi semakin besar.

Hasil uji post hoc Games-Howell pada dimensi anteroposterior mendapatkan perbedaan bermakna antara kelompok kontrol, 5 menit, 15 menit, 30 menit, dan 50 menit perendaman. Hal ini sesuai dengan hipotesis penelitian ini yaitu terdapat perbedaan stabilitas dimensi yang direndam dalam ekstrak daun teh hijau dan tanpa direndam.
Perubahan anteroposterior yang terjadi dapat diamati dari perbedaan ukuran die stone dan ukuran master die. Pada die stone terjadi pertambahan jarak $0,8 \mathrm{~mm}$ hingga 2,17 mm untuk kelompok yang direndam selama 5 menit, 15 menit, 30 menit, dan 50 menit. Hasil perendaman terbaik menurut hasil uji statistika dari penelitian ini ialah selama 5 menit karena merupakan waktu yang paling efektif untuk mengalami perubahan stabilitas dimensi hasil cetakan alginat. Hal ini terjadi karena hasil cetakan alginat berkontak dengan air dalam waktu yang relatif singkat.

Hasil uji post hoc LSD pada dimensi mediolateral menunjukkan tidak terdapat perbedaan bermakna antara kelompok kontrol dan 5 menit, tetapi terdapat perbedaan bermakna antara kelompok kontrol dengan 15 menit, 30 menit, dan 50 menit perendaman. Perubahan mediolateral yang terjadi dapat diamati dari perbedaan ukuran die stone dan ukuran master die. Pada die stone terjadi pertambahan jarak $0,7 \mathrm{~mm}$ hingga $1,27 \mathrm{~mm}$ pada kelompok yang direndam selama 5 menit, 15 menit, 30 menit, dan 50 menit. Menurut hasil uji statistika penelitian ini, perendaman terbaik ialah selama 15 menit karena terjadi perubahan stabilitas dimensi yang bermakna pertama kali. Hal ini sejalan dengan penelitian yang dilakukan oleh Santoso et al ${ }^{14}$ yang melaporkan bahwa terjadi perubahan bermakna pertama kali pada kelompok yang direndam selama 15 menit. Hasil ini sesuai dengan penelitian sebelumnya bahwa desinfeksi alginat tidak lebih dari 15 menit karena setelah didesinfeksi lebih dari 15 menit akan terjadi perubahan stabilitas dimensi alginat yang tidak sesuai dengan standar ADA yaitu lebih dari 0,5\% dari master die yang diukur.

Perubahan stabilitas dimensi terjadi karena hasil cetakan yang direndam dalam ekstrak daun teh hijau $50 \%$ mengalami proses imbibisi. Daun teh hijau memiliki kandungan fenol yang bila berkontak dengan bahan cetak alginat akan menyebabkan terjadinya reaksi esterifikasi yaitu reaksi pembentukan ester dengan cara berikatan dengan asam karboksilat yang terkandung dalam struktur kimia bahan cetak alginat. 
Reaksi esterifikasi akan menghasilkan kandungan $\mathrm{H}_{2} \mathrm{O}$. Alginat memiliki sifat yang mudah mengalami imbibisi sehingga bila ekstrak daun teh hijau yang mengandung senyawa fenol berkontak dengan alginat dapat menyebabkan ekspansi hasil cetakan. ${ }^{15}$

Pada penelitian ini dilakukan pengukuran dimensi anteroposterior dan mediolateral untuk memastikan akurasi stabilitas dimensi alginat setelah dilakukan desinfeksi agar tidak memengaruhi rencana perawatan selanjutnya. ${ }^{16}$

\section{SIMPULAN}

Hasil perendaman cetakan alginat yang terbaik ialah selama 15 menit karena dalam waktu perendaman tersebut terjadi perubahan stabilitas dimensi yang masih sesuai dengan standar American Dental Association.

\section{Konflik Kepentingan}

Penulis menyatakan tidak ada konflik kepentingan dalam penelitian ini.

\section{DAFTAR PUSTAKA}

1. Setiawan R. Penatalaksanaan relining pada gigi tiruan sebagian lepasan (GTSL). J Ilm Widya [Internet]. 2013;1(1):60.

2. Mc.Cabe JF. Bahan Kedokteran Gigi (9th ed). Jakarta: EGC, 2016; p. 362-4.

3. Sari DF, Parnaadji RR, Sumono A. Pengaruh teknik desinfeksi dengan berbagai macam larutan desinfektan pada hasil cetakan alginat terhadap stabilitas dimensional. J Pustaka Kesehat. 2013; 1(1):30.

4. Wulan KA, Fitriani D, Al-hazmy L. Perbedaan stabilitas dimensi antara hasil pencetakan polieter yang diperoleh melalui teknik pencampuran manual dan pencampuran otomatis. E-Prodenta $\mathbf{J}$ Dent. 2019;3(1):198.

5. Rad FH, Ghaffari T, Safavi SH. In vitro evaluation of dimensional stability of alginate impressions after disinfection by spray and immersion methods. J Dent Res Dent Clin Dent Prospects. 2010;4(4):130.

6. Doddamani S, Patil RA, Gangadhar SA. Efficacy of various spray disinfectants on irreversible hydrocolloid impression materials: an in vitro study. Indian J Dent Res. 2011;22(6):764.

7. $\mathrm{Xu} \mathrm{X}$, Zhou XD, Wu CD. The tea catechin epigallocatechin gallate suppresses cariogenic virulence factors of Streptococcus mutans. Antimicrob Agents Chemother. 2011;55(3):1230.

8. Ongo TA, Rachmadi P, Arya IW. Stabilitas dimensi hasil cetakan bahan cetak elastomer setelah disemprot menggunakan sodium hipoklorit. J Kedokt Gigi. 2014;2(1):84.

9. Farzin M, Panahandeh H. Effect of pouring time and storage temperature on dimensional stability of casts made from irreversible hydrocolloid. J Dent (Tehran) [Internet]. 2010;7(4):180-1.

10. Wirayuni KA, Nyoman D, Juniawati A. Teknik desinfeksi perendaman dan penyemprotan ekstrak mengkudu (Morinda Citrifolia Linn), terhadap perubahan stabilitas dimensi cetakan alginat. Sonde. 2020;5(1):42.

11. Ginting AF, Suryanto E, Momuat LI. Aktivitas antioksidan ekstrak air dan etanol dari empelur batang sagu baruk (Arenga microcarpha). Chem Prog. 2015;8(2):50.

12. Susanty S, Bachmid F. Perbandingan metode ekstraksi maserasi dan refluks terhadap kadar fenolik dari ekstrak tongkol jagung (Zea mays L.). J Konversi. 2016; 5(2):88.

13. Sumono A. Pengaruh cetakan kombinasi hidrokoloid reversibel dan irreversibel terhadap lama penyimpanan dan akurasi dimensional. Stomatognatic (J KG, UNEJ). 2006;3(1):14.

14. Santoso EDL, Widodo TT, Baehaqi M. Pengaruh lama perendaman cetakan alginat di dalam larutan desinfektan glutaraldehid 2\% terhadap stabilitas dimensi. Odonto Dent J. 2014;1(2):37-8.

15. Amelia AN, Suharti N, Rahmi E. Perbedaan stabilitas dimensi antara cetakan alginat yang diberi desinfektan ekstrak daun alpukat (Persea americana mill) dengan natrium hipoklorit. Andalas Dent $\mathrm{J}$. 2017;5(2):85.

16. Didin K. Efek imbibisi perendaman bahan cetak hydrocolloid irreversible alginate dalam larutan sodium hypochlorite. Cakradonya Dent J. 2016;8(2):93-6. 